\title{
Ultra-low molecular weight photoswitchable hydrogelators
}

\author{
Fayaz Ali Larik, ${ }^{[a, b]}$ Lucy L. Fillbrook, ${ }^{[a]}$ Sandra S. Nurttila, ${ }^{[a, b]}$ Adam D. Martin, ${ }^{[c]}$ Rhiannon P. Kuchel, ${ }^{[d]}$ \\ Karrar Al Taief, ${ }^{[a, b]}$ Mohan Bhadbhade, ${ }^{[e]}$ Jonathon E. Beves ${ }^{*[a]}$ and Pall Thordarson ${ }^{*}[a, b]$
}
[a] F. A. Larik, L. L. Fillbrook, Dr. S. S. Nurttila, K. Al Taief, Dr. J. E. Beves, Prof. Pall Thordarson
School of Chemistry
The University of New South Wales
Sydney, NSW 2052, Australia
E-mail: j.beves@unsw.edu.au and p.thordarson@unsw.edu.au
[b] F. A. Larik, Dr. S. S. Nurttila, K. Al Taief, Prof. Pall Thordarson
The Australian Centre for Nanomedicine and the ARC Centre of Excellence in Convergent Bio-Nano Science and Technology
The University of New South Wales
Sydney, NSW 2052, Australia
[c] Dr A. D. Martin
Dementia Research Centre, Department of Biomedical Science, Faculty of Medicine and Health Sciences
Macquarie University
Sydney, NSW 2109, Australia
[d] Dr. R. P. Kuchel
Electron Microscopy Unit, Mark Wainwright Analytical Centre
The University of New South Wales
Sydney, NSW 2052, Australia
[e] Dr. M. Bhadbhade
Solid State \& Elemental Analysis Unit, Mark Wainwright Analytical Centre
The University of New South Wales
Sydney, NSW 2052, Australia

Supporting information for this article is given via a link at the end of the document

\begin{abstract}
Two photoswitchable arylazopyrozoles form hydrogels at a concentration of $1.2 \%(\mathrm{w} / \mathrm{v})$. With a molecular weight of 258.28 $\mathrm{g} / \mathrm{mol}$, these are the lowest known molecular weight hydrogelators that respond reversibly to light. Photoswitching of the $E$ - to the $Z$ form by $365 \mathrm{~nm}$ light results in a macrocopic gel $\rightarrow$ sol transition; nearly an order of magnitude reduction in the measured elastic and loss moduli. In the case of the meta-arylazopyrozole, cryogenic transmission electron microscopy suggests that the $29 \pm 7 \mathrm{~nm}$ wide sheets in the $E$-gel state narrow to $13 \pm 2 \mathrm{~nm}$ upon photoswitching to the predominantly Z-solution state. Photoswitching for metaarylazopyrozole is reversible through cycles of $365 \mathrm{~nm}$ and $520 \mathrm{~nm}$ excitation with little fatigue. The release of a Rhodamine B dye encapsulated in gels formed by the arylazopyrozoles is accelerated more than 20-fold upon photoswitching with $365 \mathrm{~nm}$ light, demonstrating these materials are suitable for light-controlled cargo release.
\end{abstract}

\section{Introduction}

The formation of cytoskeletal filaments ${ }^{[1]}$ and flagellar filaments of bacteria ${ }^{[2]}$ rely on the self-assembly of smaller components. Synthetic small molecules have also been shown to selfassemble in water to form structures ranging from the nanometer scale to micrometer scale,$^{[3]}$ with hydrogelator ${ }^{[4]}$ being one example. Controlling the self-assembly of hydrogels using external stimuli has been challenging ${ }^{[5]}$ but can be achieved by introducing the appropriate responsive units within the molecular components of these systems.

Hydrogel research ${ }^{[4]}$ has evolved from static materials to dynamic smart materials. Controlling the mechanical, physical and chemical properties of hydrogels with external stimuli is important for both medical and industrial uses such as controlled drug delivery, ${ }^{[6]}$ sensing, ${ }^{[7]}$ robotics ${ }^{[8]}$ and $3 D$ cell cultures ${ }^{[9]}$ Light has a clear advantage due to its ability to operate in a highly precise manner without contaminating samples. ${ }^{[10]}$ Hydrogels have been made light responsive by the inclusion of a light responsive photoswitchable unit in the gelator molecule. ${ }^{[10 c, 10 \mathrm{~d}]}$ All previous examples have relied on the inclusion of peptides or other additional groups to enable hydrogel formation (Figure 1a,b). Peptide-[11,10c,10d] or polymer-based ${ }^{[12]}$ hydrogels have been rendered photoresponsive by introducing molecular photoswitches such as diarylethene, ${ }^{[13]}$ spiropyran, ${ }^{111,14 a, 10 d, 14 b]}$ azobenzene, ${ }^{[15 a-l, 10 e, 15 \mathrm{~m}, 15 \mathrm{n}]}$ stilbene, ${ }^{[16]}$ orthofluoroazobenzenes, ${ }^{[17]}$ and arylazopyrazoles. ${ }^{[18,12 c]}$

Arylazopyrazoles (AAP) are a recently introduced class of azohetereoarene photoswitches. ${ }^{[19]}$ Azoheteroarenes ${ }^{[19 c]}$ are related to azobenzenes but differ as one of the phenyl rings of conventional azobenzene is replaced with heteroarene ring. The Fuchter group has extensively studied these compounds showing almost complete photoisomerization in both directions with the thermal half-life of the metastable Z-isomer being tunable from hours to 10 days. ${ }^{[19]}$ Ravoo and co-workers ${ }^{[20]}$ have used arylazopyrazoles to form light responsive gels where a central linker is connected to three photoswitching groups (Figure 1b, MW=1195.27 g/mol). Tetrapeptides gelators (FmocRGDS) were combined with an arylazopyrazole photoswitching unit attached via a linker chain (Fmoc-RGDS-AAP). ${ }^{[20]}$

Most gelators reported in literature, including all photoswitchable gelators, have a MW > $300 \mathrm{~g} / \mathrm{mol}$. The bulk of light-responsive gelators contain long alkyl chains, peptides, or polymers and hence the photoswitchable unit plays a secondary role in the self-assembly of these systems. Herein we introduce the first gelators with a molecular weight below 300 (MW= $258.28 \mathrm{~g} / \mathrm{mol}$ - making it one of smallest hydrogelator reported ${ }^{[21]}$ ) that form stable hydrogels at physiological $\mathrm{pH}$ and respond to light in a bidirectional way (Figure 1c,d). 
a) Previous work:<smiles>Cc1cc(C2=C(c3cc(C)sc3C)C(=O)N(CC(=O)NC(CCCCN)C(=O)NCC(=O)O)C2=O)c(C)s1</smiles>
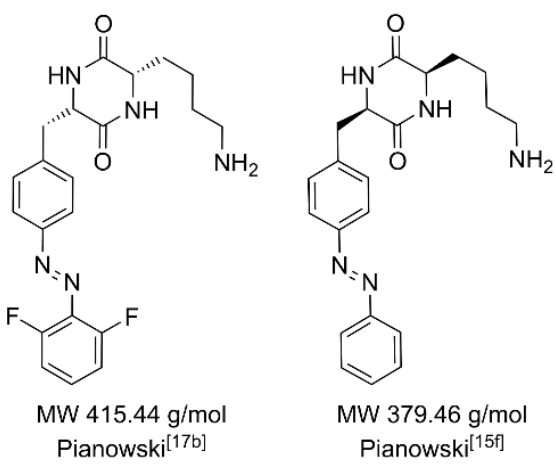

MW $379.46 \mathrm{~g} / \mathrm{mol}$ Pianowski ${ }^{[15 f]}$ b)<smiles>[R]NC(=O)[C@H]1C[C@H](C(=O)N[R])C[C@@H](C(=O)N[R])C1</smiles>

c) This work:<smiles>Cc1nn(C)c(C)c1/N=N/c1ccccc1C(=O)O</smiles>

E-1

MW $258.28 \mathrm{~g} / \mathrm{mol}$ non-gelator<smiles>Cc1nn(C)c(C)c1/N=N/c1cccc(C(=O)O)c1</smiles>

E-2

MW $258.28 \mathrm{~g} / \mathrm{mol}$ fully reversible gelator<smiles></smiles>

MW $258.28 \mathrm{~g} / \mathrm{mol}$ irreversible gelator

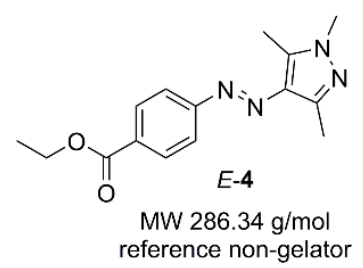

d)

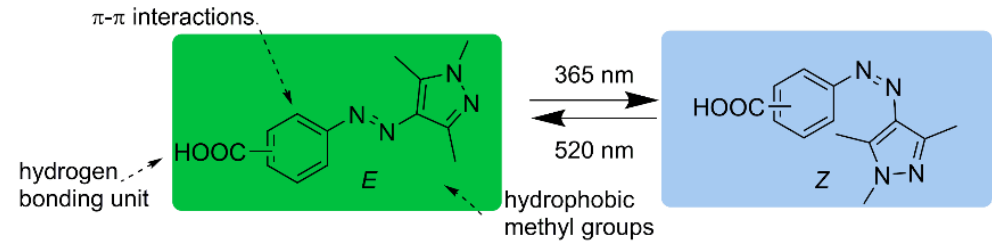

Figure 1. a) The three smallest photoswitchable single-component hydrogelators reported to date. b) The smallest single-component arylazopyrazole photoswitchable gelator previously reported. c) The low molecular weight photoswitching arylazopyrazole compounds 1-4 (in their E-form) reported in this work. Compounds 2-3 (MW $258.28 \mathrm{~g} / \mathrm{mol}$ ) form gel in water at $1.0 \%(\mathrm{w} / \mathrm{v})$, while 1 and control compound 4 do not form gels reported here. d) The design and switching mechanism of low molecular weight photoswitchable gelators 1-3.

Arylazopyrazole photoswitches 1-3 (Figure 1c) are isomers that differ only in the substitution of the carboxylic acid group on the aromatic ring. The carboxylic acid group can act as a hydrogen bond donor and acceptor, and the pyrazole ring and the diazo nitrogens can act as hydrogen bond acceptors to aid the gelation process. The photoswitches $\mathbf{2}$ and $\mathbf{3}$ form hydrogels as a result of intermolecular hydrogen bonding and hydrophobic effects, and represent the minimal non-covalent interactions usually required to trigger gelation. The arylazopyrazole photoswitch 4 bears an ester group at the para position and is used as a control compound not capable of intermolecular hydrogen bonding and hence does not form a gel.

\section{Results and Discussion}

\section{Synthesis of photoswitches 1-4}

Compounds 1-4 were synthesized using modified literature procedures of related compounds. ${ }^{[19 b]}$ The ortho-, meta- or paraaminobenzoic acid and ethylaminobenzoate were reacted with hydrochloric acid and sodium nitrite to form the diazonium salt, which was reacted with acetylacetone to obtain pentane-2,4diones (S1-S4) intermediates (see full characterization in SI-2, SI-12, SI-13, analytical methods described in SI-3). The intermediates (S1-S4) were refluxed for $3 \mathrm{~h}$ with $\mathrm{N}$-methylamine and then concentrated under reduced pressure to obtain 1-4 as yellow solids in quantitative yields.

The photoswitching behavior of 1-4 was evaluated by UVvis absorption (SI-4) and NMR spectroscopy (SI-12). Photoswitching using UV-vis absorption was recorded in a range of solvents (DMSO, $\mathrm{CH}_{2} \mathrm{Cl}_{2}$, methanol, THF, ethyl acetate, chloroform, toluene and acetonitrile) and the spectra in water are shown in Figure 2a. No significant solvatochromism was observed between the eight solvents that were studied (Table S2-S5). The samples were irradiated with $365 \mathrm{~nm}$ and $520 \mathrm{~nm}$ LED light sources for $\sim 2 \mathrm{~min}$ to generate photostationary states (PSS) enriched in the Z- or E-isomer, labelled $\mathrm{PSS}_{Z}$ and $\mathrm{PSS}_{E}$ respectively. The data is in agreement with that observed for related arylazopyrazole compounds. ${ }^{[19 b}$

The PSS compositions were quantified by ${ }^{1} \mathrm{H}$ NMR spectroscopy. The ${ }^{1} \mathrm{H}$ NMR spectra in DMSO- $d_{6}$ of samples equilibrated in the dark showed a single isomer in each case, the expected thermodynamically stable E-isomer (see SI-12.9, SI-12.16, SI12.23 and SI-12.27). The samples were irradiated with $365 \mathrm{~nm}$ light for $60 \mathrm{~min}$ and ${ }^{1} \mathrm{H}$ NMR spectra were recorded to obtain the PSS distribution PSS $_{Z} \approx 90 \%$ Z for each of $\mathbf{1 - 4}$, see SI-12.11, SI-12.18, SI-12-25, SI-12.29). Each sample was then irradiated with $520 \mathrm{~nm}$ light to produce a new photostationary state PSS $_{E}$ $\approx 92 \%$ Figure $2 \mathrm{c}$ ). The $\mathrm{PSS}_{Z}$ is thermally stable at $25^{\circ} \mathrm{C}$ in water over the time scale relevant to all the studies in this work with an 
apparent half-life measured by UV-vis absorption of 29-34 $\mathrm{h}$ for compounds 1-4 (Figures S7, S12, S17, S22) All the compounds showed excellent photoswitching behavior in water and DMSO$d_{6}$.
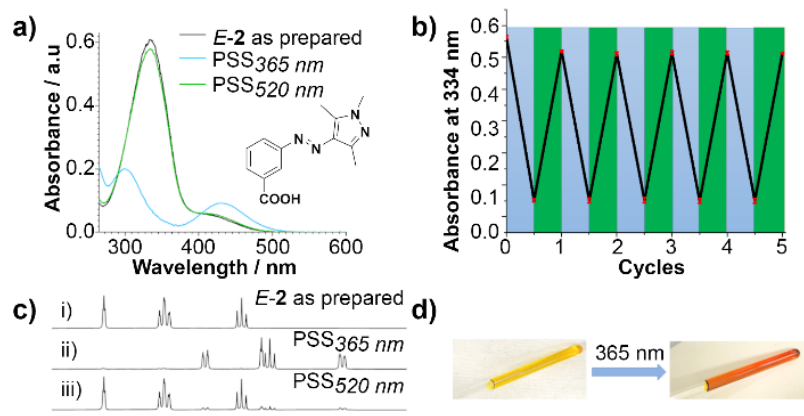

$\begin{array}{llllllll}8.4 & 8.2 & 8.0 & 7.8 & 7.6 & 7.4 & 7.2 & 7.0\end{array}$ ppm

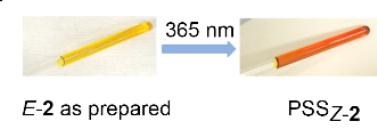

Figure 2. Photoswitching of 2 monitored by a) UV-vis absorption spectra in water of $E-2$ as prepared (black line) and at photostationary states upon irradiation with $365 \mathrm{~nm}$ (blue line) and $520 \mathrm{~nm}$ (green line) light. b) Reversible switching of absorption in water monitored at $334 \mathrm{~nm}$ upon alternating irradiation with UV ( $365 \mathrm{~nm}$, indicated with blue) and green $(520 \mathrm{~nm})$ light (red error bars $= \pm 1$ std from $n=3$ measurements). c) ${ }^{1} \mathrm{H}$ NMR $(400 \mathrm{MHz}$, DMSO$\left.d_{6}\right)$ of i) as prepared $E-2$, ii) after irradiation with UV $(365 \mathrm{~nm})$ or iii) green (520 $\mathrm{nm}$ ) light. d) NMR tube of E-2 in DMSO- $d_{6}$ as prepared and $\mathrm{PSS}_{z}$ obtained after irradiation with $365 \mathrm{~nm}$ light. See Figure SI-4, SI-12 for similar data on 1, 3 and 4.

\section{Solid state interactions}

Crystals suitable for single crystal X-ray diffraction were grown of 1-4 from saturated solutions in DMF/diethyl ether, DMSO and ethanol (SI-6 for details). The structure of 1 showed an intramolecular hydrogen bond between the carboxylic acid group and the adjacent diazo nitrogen $(\mathrm{O} \cdots \mathrm{N}=2.595(7) \AA)$. Compound 2 is slightly twisted, with an angle of $20.1^{\circ}$ between the least-squares planes of the phenyl- and the pyrazole rings. By comparison compound $\mathbf{3}$ is almost completely flat, with the same angle between the two rings being just $5.39^{\circ}$. The structures of both $\mathbf{2}$ and $\mathbf{3}$ show inter-molecular hydrogen bonds between the carboxylic acid group and the free pyrazole nitrogen of an adjacent molecule, with short and similar $\mathrm{N} \cdots \mathrm{O}$ distances (2.712(4) and 2.689(2) ^̊, respectively. In each case the hydrogen bonds result in 1D chains that are self-assembled by $\pi-\pi$ interactions (centroid-to-plane distances of $3.34 \AA$ and $3.30 \AA$ for 2 and 3 respectively, see Figure $3 b$, $d$ and Table 1). Details for the structures of $\mathbf{1}$ and $\mathbf{4}$ are given in SI-6.

Hirshfeld surface analysis ${ }^{[22]}$ is a powerful tool for visualizing short and long contacts within crystal structures. The so-called "fingerprint" plots of 2-3 (SI-7) are superficially very similar, highlighting the importance of the two intermolecular shorts contacts show in Figures 3a and 3c. However, the Hirshfeld fingerprint of 3 highlights a significant pairwise intermolecular $\mathrm{H}$... $\mathrm{O}$ interaction between the carbonyl oxygen and an aromatic meta-hydrogen on a neighboring molecule. This suggests why gelator 3 packs in an antiparallel fashion in the single crystal structure, in contrast to gelator 2 . Previous studies have shown similar pair-wise interaction drive the formation of antiparallel stacked aromatic molecules. ${ }^{[23]}$ No significant intermolecular short contacts were observed in the Hirshfeld fingerprint plot of 1
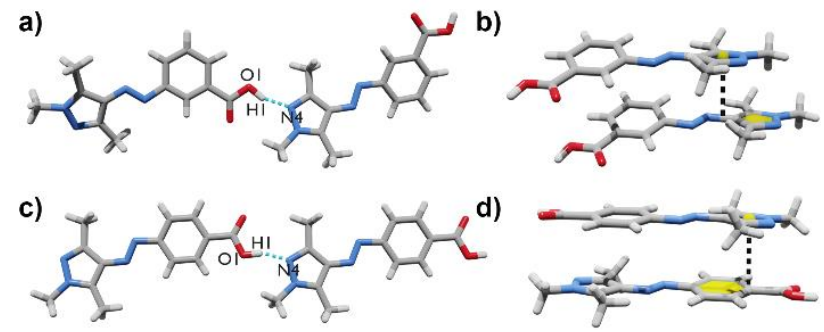

Figure 3. Single crystal X-ray structures of a-b) 2 and c-d) 3 . The ortho derivative 1 has an intramolecular hydrogen bond and does not form extended chains (SI-6.5). Both the meta-2 and para-derivatives 3 form 1D hydrogen bonded chains as shown. Centroid-to-plane distances are shown with black dotted lines.

Table 1. Comparison of the key parameters of hydrogen bonding of isomers 1-3, obtained from the single crystal X-ray diffraction data.

\begin{tabular}{lccc}
\hline Inter/Intra & $\begin{array}{c}\mathbf{1} \\
\text { Intra- }\end{array}$ & $\begin{array}{c}\mathbf{2} \\
\text { Inter- }\end{array}$ & $\begin{array}{c}\mathbf{3} \\
\text { Inter- }\end{array}$ \\
\hline $\mathrm{O}-\mathrm{H} / \AA$ & 0.840 & $0.98(4)$ & $0.94(2)$ \\
$\mathrm{H} \cdots \mathrm{N} / \AA$ & 1.822 & 1.774 & 1.793 \\
$\mathrm{O} \cdots \mathrm{N} / \AA$ & $2.595(7)$ & $2.712(4)$ & $2.689(2)$ \\
$\mathrm{O}-\mathrm{H} \cdots \mathrm{N} / \mathrm{O}$ & 152.3 & $160(4)$ & $160(2)$ \\
\hline
\end{tabular}

(Figure S70) due to the intramolecular hydrogen bond between the carboxylic acid and the diazo nitrogen.

\section{Hydrogel formation}

Gelation was investigated using the $\mathrm{pH}$ switch method with glucono- $\delta$-lactone $(g \delta \mathrm{L}) .{ }^{[24]}$ All the starting materials were in the pure $E$-form and these experiments were carried out in the absence of light. Compounds $\mathbf{2}$ and $\mathbf{3}$ were dissolved at $\mathrm{pH}$ 11, followed by the addition of $\mathrm{g} \delta \mathrm{L}$. After standing at room temperature overnight, hydrogels were formed as determined by the inverted vial test (see SI-9). The minimum gelation concentration for both gelators was determined to be $1.0 \%(\mathrm{w} / \mathrm{v})$, however, to ensure better consistency in gel properties, all subsequent studies were carried out at $1.2 \%(\mathrm{w} / \mathrm{v})$ concentration of $\mathbf{2}$ and $\mathbf{3}$. The kinetics of gelation of compounds $\mathbf{2}$ and $\mathbf{3}$ was monitored by ${ }^{1} \mathrm{H}$ NMR spectroscopy (see SI-11). The disappearance of the ${ }^{1} \mathrm{H}$ NMR signals of the monomeric gelator over $\sim 80 \mathrm{~min}$ for $\mathbf{2}$ or $\mathbf{3}$ was consistent with aggregation. Compound 1, which does not form any intermolecular hydrogen bonds in the solid state, does not form a gel in water (SI-8.1). Compound 4, which also does not display any solid-state intermolecular hydrogen bonding interactions (SI-6.8), does not form a gel. The $\mathrm{p} K_{\mathrm{a}}$ values of compound 1-3 are practically indistinguishable (determined by $\mathrm{pH}$ titrations, see $\mathrm{SI}-10$ ) with pKa values of $6.4,6.4$ and 6.7 for $\mathbf{1 , 2}$ and $\mathbf{3}$, respectively.

The viscoelastic properties of gels formed by 2 and 3 were studied using a rheometer (Table 2, SI-3). In the dark, the gel formed by 2 was stiffer (elastic modulus $\mathrm{G}^{\prime} \sim 10 \mathrm{kPa}$ ) than that of $3\left(\mathrm{G}^{\prime} \sim 1.2 \mathrm{kPa}\right)$; both were prepared by the $\mathrm{pH}$ switch method using $\mathrm{g} \delta \mathrm{L}(1.2 \%(\mathrm{w} / \mathrm{v})$; dissolved in $0.1 \mathrm{M}$ sodium hydroxide, followed by the addition of $\mathrm{g} \delta \mathrm{L}$, see $\mathrm{SI}-3$ ). The frequency sweeps (SI-8.4-8.5) showed that the storage modulus is 
independent of the applied frequencies up to $\approx 10 \mathrm{~Hz}$ with some frequency hardening observed at higher frequencies. The strain sweep (SI-8.2) for both 2 and 3 showed that both hydrogels possess malleable-like characteristics, with the linear viscoelastic region lasting until about $10 \%$ strain for both gelators. Further increases in strain result in gel collapse at about $60 \%$ and $80 \%$ strain for 2 and 3 , respectively.

Table 2. Key physical properties of gels formed by $\mathbf{2}$ and $\mathbf{3}$ in the dark.

\begin{tabular}{ccccc}
\hline Gelator & mgc $^{[\mathrm{a}]}$ & $\mathrm{G}^{\prime}{ }^{\mathrm{b}]}$ & LVR $^{[\mathrm{c}]}$ & Fiber diameter $^{[\mathrm{d}]}$ \\
\hline $\mathbf{2}$ & $1 \%(\mathrm{w} / \mathrm{v})$ & $10 \mathrm{kPa}$ & $10 \%$ & $12.2 \pm 0.5 \mathrm{~nm}$ \\
$\mathbf{3}$ & $1 \%(\mathrm{w} / \mathrm{v})$ & $1.2 \mathrm{kPa}$ & $9.5 \%$ & $13.4 \pm 0.6 \mathrm{~nm}$ \\
\hline
\end{tabular}

[a] Minimum gelation concentration (mgc). [b] Elastic modulus (G') at strain = $1 \%$, frequency $=1 \mathrm{~Hz}$ and $1.2 \%$ (w/v) concentration. [c] Elasticity (strain) or linear viscoelastic region (LVR) at frequency $=1 \mathrm{~Hz}$. [d] Histograms of the fiber heights obtained from AFM microscopy and measured for 2 and 3 before irradiation with light. The histograms represent 25 measurements in four different areas for each sample (bin size $=100$ ).

We postulate here that the approximately one order of magnitude difference in the elastic modulus of gels formed by 2 and 3 in the dark can be explained with reference to the observed parallel versus anti-parallel packing in the single crystal structures of $\mathbf{2}$ and $\mathbf{3}$, respectively. Powder X-ray diffraction of xerogels formed from 2 and 3 yielded patterns similar to those predicted from the single crystal X-ray structures (SI-6.11, SI-6.12). The single crystal X-ray structure data and Hirshfeld surface analysis in turn indicate that pairwise intermolecular $\mathrm{H} \cdots \mathrm{O}$ interactions drive the slightly less compact packing of $\mathbf{3}$ in an antiparallel orientation.

\section{Gel $\rightarrow$ Sol Photoswitching}

Immediately after the addition of $\mathrm{g} \delta \mathrm{L}, 1.2 \%(\mathrm{w} / \mathrm{v})$ solutions of 2 and $\mathbf{3}$ were cast onto a rheometer fitted with a glass plate and allowed to form hydrogel in dark over $\sim 85 \mathrm{~min}$. Dynamic in situ time sweep rheological measurements were conducted on 2 and 3 upon exposure to alternating $365 \mathrm{~nm}$ and $520 \mathrm{~nm}$ light. As the illuminated area is significantly smaller than the diameter $(25$ $\mathrm{mm}$ ) of the rheometer measurement plate, the $\approx 500 \mu \mathrm{L}$ gap was only filled with ca $20 \%(110 \mu \mathrm{L})$ of the gel solution. The absolute elastic (G') and loss (G') module obtained are therefore not directly comparable to the rheological data obtained under standard conditions in the dark discussed above (see SI-3.8 for further information).

Upon the first irradiation with $365 \mathrm{~nm}$ UV light, G' for 2 decreased from about $200 \mathrm{~Pa}$ to about $50 \mathrm{~Pa}$ over a period of 1 h (Figure 4). Subsequent irradiation of 2 with $520 \mathrm{~nm}$ green light restored the initial elasticity of 2 (see Figure $4 \mathrm{a}$ ). Both green and UV light-irradiated states retained stable G' values for at least $15 \mathrm{~min}$ after the light was switched off. Multiple photoswitching cycles were performed on 2 by alternating between UV and green light irradiation and minimal fatigue was observed.

While a gel $\rightarrow$ sol transition appears to have occurred using a conventional inversion test on 2 (Figure 4) and $\mathbf{3}$ (Figure S76), the $\tan \delta$ (the G'/G' ratio) remains well below 1-the conventional rheological definition of a gel[4b]—during the entire course of the light-switching experiments (Figure S75). Strong arguments have been made in the literature that a $\tan \delta<1$ is a more reliable indicator of gelation than the inversion test, albeit that argument is usually in the situation whereby the materials appears to pass the inversion test while $\tan \delta>1 .{ }^{[4 b, 25]}$ Here, the opposite situation was observed, which is in line with recent observation by Adams and co-workers who attribute this phenomena to the formation of a structured liquid ${ }^{[26]}$ (a liquid with some remaining solid-like rheological properties), but further work is required to explain why irradiation of $\mathbf{2}$ and $\mathbf{3}$ leads to an apparent gel transition despite the fact that $\tan \delta<1$.
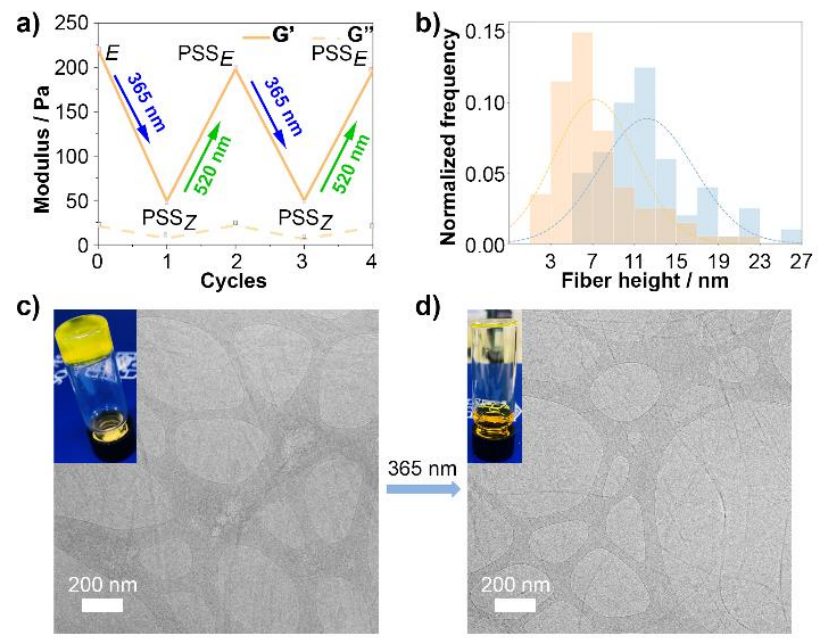

Figure 4. Photoswitching of 2 by alternating irradiation with $365 \mathrm{~nm}$ and 520 $\mathrm{nm}$ light. Changes in a) rheology with in situ irradiation and b) Size of fibers obtained from AFM microscopy before (blue) and after irradiation (orange) after drop casting dilute $(0.0006 \%, \mathrm{w} / \mathrm{v})$ solution of $\mathbf{2}$ on to a mica surface. Morphology of fibers obtained from cryo-TEM microscopy of gels formed from 2 in water $(1.2 \%(w / v))$ c) before light and d) after irradiation with $365 \mathrm{~nm}$ light, scale bar is $200 \mathrm{~nm}$. For the analogous data for compound 3, see SI-5.3.6 and SI-8.4.

\section{Microscopy studies of gel morphology}

Atomic force microscopy (AFM) measurements were conducted starting with $1.2 \%(\mathrm{w} / \mathrm{v})$ solutions of $1-4$ that were then rapidly diluted (to $0.0006 \% \mathrm{w} / \mathrm{v}$ ) and drop casted on a mica substrate to investigate the size and topography of any selfassembled fibers formed under such conditions (SI-5.1). We have previously shown that AFM measurements on fibers formed from dilute drop-cast solutions yield comparable information to more experimentally challenging cryogenic transmission electron microscopy (cryo-TEM) and in situ small angle neutron scattering (SANS) methods. ${ }^{[27]}$ No fibers were found for compounds $\mathbf{1}$ and $\mathbf{4}$, which is in line with the observation that they did not self-assemble into gels. Compound 2 formed fibers with a diameter of $12.2 \pm 0.5 \mathrm{~nm}$ (in the dark) and when irradiated with $365 \mathrm{~nm}$ light the diameter of the fibers reduced to $7.2 \pm 0.4 \mathrm{~nm}$, as measured by AFM (Figure $4 \mathrm{~b}$ ). Similarly, compound $\mathbf{3}$ formed thin sheet-like fibers with a diameter of $13.4 \pm 0.5 \mathrm{~nm}$ (in the dark) and $4.7 \pm 0.3 \mathrm{~nm}$ (after irradiation with $365 \mathrm{~nm}$ ). On all occasions, the fibers appear longer than the maximum scan size used $(5 \times 5 \mu \mathrm{m})$. Scanning electron microscopy (SEM) was used to image the structures formed from 1-4 when more concentrated $1.2 \%(\mathrm{w} / \mathrm{v})$ solutions (in the dark) were drop-cast onto silica (SI-5.2). The desiccated gels from 2 and 3 showed fiber-like surfaces, while the precipitates from compounds $\mathbf{1}$ and $\mathbf{4}$ were found to have crystal-like surfaces (SI-5.2.1, SI-5.2.4). If the solutions were 
irradiated with $365 \mathrm{~nm}$ light prior to being drop-cast, the morphology observed for $\mathbf{2}$ and $\mathbf{3}$ changed from fibrous to crystalline, consistent with disassembly (see SI-5.2.2, SI-5.2.3).

The combination of TEM and cryo-TEM techniques were used to investigate the structural changes in the self-assembly of 2 and 3 before and after illumination with $365 \mathrm{~nm}$ light (SI-5.3). When comparing the cryo-TEM micrographs of the fibers from gels formed by 2 at $1.2 \%(\mathrm{w} / \mathrm{v})$ in water before (Figure $4 \mathrm{c}$ ) and after irradiation with $365 \mathrm{~nm}$ light (Figure 4d), a clear "thinning" of the fibers is observed, as the $29 \pm 7 \mathrm{~nm}$ wide sheets narrow down to $13 \pm 2 \mathrm{~nm}$. These results are qualitatively consistent with the AFM analysis above, given that the latter are presumably dried out. This data is supported by conventional TEM analysis on $1.2 \%(\mathrm{w} / \mathrm{v})$ solutions of 2 (SI-5.3.2). Compounds 1 and $4 \mathrm{did}$ not show any fiber-like aggregates under these conditions. TEM analysis of $\mathbf{3}$ was less conclusive; conventional TEM did not show fibers but rather spherical, perhaps micellar-like objects prior to illumination that disintegrated upon illumination with 365 $\mathrm{nm}$ light (SI-5.3.3). The cryo-TEM micrographs of 3 before illumination showed very wide $(\approx 400 \mathrm{~nm})$ thin sheet like structures that do also become thinner $(\approx 200 \mathrm{~nm})$ after irradiation with $365 \mathrm{~nm}$ light (SI-5.3.6), which appear in some cases less than $1 \mu \mathrm{m}$ long.

In an attempt to investigate the further the observed "thinning" and the mechanism of assembly/disassembly upon photoswitching, ${ }^{1} \mathrm{H}$ NMR studies were carried out on gels formed from 2 and 3 (SI 11.1). In both cases, switching the initially prepared gels to $\mathrm{PSS}_{z}$ with a $365 \mathrm{~nm}$ light source resulted in sharp peaks indicating that $\mathbf{2}$ and $\mathbf{3}$ are freely mobile in the "sol" state, although in both cases, the signal intensity did not fully recover and some precipitates were visible in the NMR tube. For the "as prepared" gel from 2 , some residual broad signals from 2 were observed in the gel state which were not present in the $\mathrm{PSS}_{E}$ gel state that was generated upon switching the sol Z-2 $\mathrm{PSS}_{Z}$ back to Z-2 PSS $E$ with the $520 \mathrm{~nm}$ light source. This suggests that the gel initially formed by "as prepared" $E-2$ differs significantly from the E-2 PSS $E$ gel state, most likely as the they are formed by two different kinetic pathways. In contrast, no residual signals where observed in the "as prepared" gel from $E$ 3 but after switching to Z-3 $\mathrm{PSS}_{Z}$ sol with a $365 \mathrm{~nm}$ light and then back to a E-3 $\mathrm{PSS}_{E}$ state with a $520 \mathrm{~nm}$ light source resulted in a loss of the NMR signals and precipitation in the NMR tube. This indicates the poor solubility of $\mathbf{3}$ in water and that the initially observed gel formation for "as prepared" $E-3$ is most likely a kinetic product, which up on rearrangement (apparent thinning) will start to precipitate in the $\mathrm{PSS}_{Z}$ state and even more so in the $\mathrm{PSS}_{E}$ state. For 2, the aggregates in the sol Z-2 $\mathrm{PSS}_{Z}$ state are probably different in nature and they then go on to form a gel again in the E-2 $\mathrm{PSS}_{E}$ state but further studies will be required to elucidate this mechanism in details.

\section{Photocontrolled dye release from gels}

Hydrogels formed with compounds 2 or $\mathbf{3}$ can be used for controlled cargo release. ${ }^{[20]}$ The fluorescent dye Rhodamine B was encapsulated during the hydrogel formation. The hydrogels were formed at the bottom of a quartz cuvette and allowed to gel overnight (see SI-3.15 for details). Water was carefully layered over the gels and the dye release was monitored by fluorescence emission spectroscopy (Figure 5). In the dark, gels of 2 and 3 released $15-25 \%$ of the dye load over $4 \mathrm{~h}$ (most of this due to the initial burst release of Rhodamine B). Upon continuous irradiation with $365 \mathrm{~nm}$ light, the gels readily released the dye, reaching approximately $80-90 \%$ dye release over $4 \mathrm{~h}$

a)

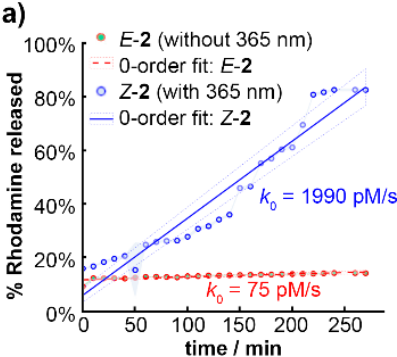

b)

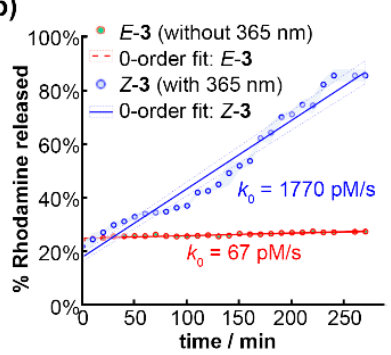

c)

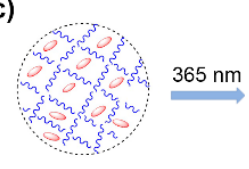

d)

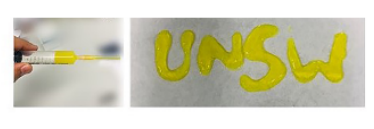

Figure 5. a) Release of Rhodamine B dye from hydrogels formed by a) 2 or b) 3 prepared by dissolving $1.2 \%(\mathrm{w} / \mathrm{v})$ of 2 or 3 and $0.01 \%(\mathrm{w} / \mathrm{v})$ of the dye in a solution of sodium hydroxide $(98 \mathrm{mmol} / \mathrm{L})$, followed by the addition of $0.16 \%$ $(w / v) g \delta$ L. The samples were continually irradiated with UV light $(365 \mathrm{~nm})$ from above for the duration of the experiment. Release was monitored by fluorescence emission spectroscopy $\left(\lambda_{\mathrm{ex}}=540 \mathrm{~nm}, \lambda_{\mathrm{em}}=576 \mathrm{~nm}\right)$, relative to complete release of the dye following by adding excess solvent to the top of the gel sample. Solid lines: Fitted release according to a zero-order kinetic model based on the zero-order rate constant $\left(k_{0}\right)$ shown. Dotted lines indicate \pm 1 standard deviations (std) of the fitted zero-order kinetics. Circles: Averages of $n=3$ repeat measurement of Rhodamine B releases. Shaded bands around the circles: \pm 1 std of the $n=3$ repeat measurements. c) Cartoon representation of dye release from hydrogels upon irradiation with $365 \mathrm{~nm}$ light. d) Injectability: a gel formed by 3 can be pushed through a syringe to form a pattern.

The release of Rhodamine B from the hydrogel formed by 2 and $\mathbf{3}$ follow zero-order kinetics $\left(k_{0}\right)$, which is usually considered desirable in second generation drug delivery systems. ${ }^{[28]}$ More importantly, the rate of Rhodamine B release from gels formed by $E-2$ and $E-3$ increased more than 20 -fold upon irradiation with a $365 \mathrm{~nm}$ light source, or from $k_{0}=75 \pm 11 \mathrm{pM} / \mathrm{s}$ for $E-2$ to $1990 \pm 110 \mathrm{pM} / \mathrm{s}$ for $Z-2$ and $k_{0}=67 \pm 8 \mathrm{pM} / \mathrm{s}$ for $E-3$ to $1770 \pm 80$ $\mathrm{pM} / \mathrm{s}$ for $Z-3$. This can be readily explained by the fact that the $365 \mathrm{~nm}$ excitation triggers a gel $\rightarrow$ sol transition for these hydrogels over a period of $\approx 200 \mathrm{~min}$ (Figure 5 ). Hydrogels formed by 2 and 3 also show good thixotropic properties at $37^{\circ} \mathrm{C}$ (SI-8.3), indicating that they can be readily injected with syringe (Figure $5 \mathrm{~d}$ ) - an advantageous property for application of these gels in light-controlled release systems.

\section{Conclusion}

Four photoswitchable arylazopyrazoles derivatives were synthesized, of which two form hydrogels at $1.2 \% \mathrm{w} / \mathrm{v}$. The meta- and para-arylazopyrazoles $\mathbf{2}$ and $\mathbf{3}$, respectively, are the lowest molecular weight photoswitchable hydrogelators reported to date. This is significant as small hydrogelators can reveal important details of gelation mechanisms by reducing degrees of freedom. Using a $365 \mathrm{~nm}$ light source, photoswitching of gels formed from the as synthesized $E-2$ and $E-3$, to the corresponding photostationary state predominantly forms 
(>90\%) Z-2 and Z-3. This results in nearly an order of magnitude reduction in the elastic (G') and loss (G') modulus. Detailed microscopy studies, including cryo-TEM imaging, suggests that this transition is associated with significant thinning of the gel fibers and in the case of $\mathbf{3}$, eventually irreversible precipitation or crystallization. Noting that the initially formed gel from $E-2$ is different from those formed from photoisomerized $E-2 \mathrm{PSS}_{E}$, the rheological properties of $\mathbf{2}$ are reversible multiple times upon repeated switching between a 365 and $520 \mathrm{~nm}$ light sources, whereas for $\mathbf{3}$ they are not, and precipitation is observed. These observation highlight that gelation is a kinetic process and the starting points when gelation is triggered by a $\mathrm{pH}$ switch are significantly different from when the aggregates are photoisomerized. The light inducted gel $\rightarrow$ sol transition for gels formed from 2 and $\mathbf{3}$ can be used to accelerate more than 20fold the release of an encapsulated dye in these gels, suggesting that these low-molecular hydrogelator could be used for light-controlled release systems in water at physiologically relevant $\mathrm{pH}$. The insight that the structural simple and photoswitchable hydrogelators $\mathbf{2}$ and $\mathbf{3}$ have given here into the mechanism of hydrogel assembly and disassembly is likely to aid the design of other related light-controlled materials and systems in the future.

\section{Acknowledgements}

This work was supported by the Australian Research Council (FT170100094 to JEB and CE140100036 \& DP190101892 to PT) and UNSW Sydney through a PhD TFS award to FAL. We acknowledge access and support from the facilities of the Mark Wainwright Analytical Centre at UNSW Sydney. We like to thank Dr Shyamal Prasad at UNSW Sydney for LED power measurements and Mr. Ashish Kumar at Anton Paar.

Keywords: arylazopyrazole $\cdot$ gels $•$ low molecular weight gelator - photoswitch $\cdot$ self-assembly

[1] K. Yonekura, S. Maki, D. G. Morgan, D. J. DeRosier, F. Vonderviszt, K. Imada, K Namba, Science 2000, 290, 2148-2152.

[2] E. J. Cohen, J. L. Ferreira, M. S. Ladinsky, M. Beeby, K. T. Hughes, Science 2017, 356, 197-200.

[3] D. Dattler, G. Fuks, J. Heiser, E. Moulin, A. Perrot, X. Yao, N. Giuseppone, Chem. Rev. 2019, 120, 310-433.

[4] a) X. Du, J. Zhou, J. Shi, B. Xu, Chem. Rev. 2015, 115, 13165-13307; (b) E. R. Draper, D. J. Adams, Chem 2017, 3, 390-410; c) S. Mondal, S. Das, A. K. Nandi, Soft Matter 2020, 16, 1404-1454.

[5] a) M. D. Segarra-Maset, V. J. Nebot, J. F. Miravet, B. Escuder, Chem. Soc. Rev. 2013, 42, 7086-7098; b) J. Hoque, N. Sangaj, S. Varghese, Macromol. Biosci. 2019, 19, 1800259.

[6] J. Hu, S. Liu, Acc. Chem. Res. 2014, 47, 2084-2095.

[7] M. Ikeda, T. Tanida, T. Yoshii, K. Kurotani, S. Onogi, K. Urayama, I. Hamachi, Nat. Chem. 2014, 6, 511-518.

[8] S. Wei, W. Lu, X. Le, C. Ma, H. Lin, B. Wu, J. Zhang, P. Theato, T. Chen, Angew. Chem. Int. Ed. 2019, 58, 16243-16251.

[9] X. Q. Dou, C. L. Feng, Adv. Mat. 2017, 29, 1604062.

[10] a) V. Balzani, A. Credi, M. Venturi, Chem. Soc. Rev. 2009, 38, 15421550; b) D. Habault, H. Zhang, Y. Zhao, Chem. Soc. Rev. 2013, 42 7244-7256; c) E. R. Draper, D. J. Adams, Chem. Commun. 2016, 52, 8196-8206; d) X. Li, J. Fei, Y. Xu, D. Li, T. Yuan, G. Li, C. Wang, J. A. Li, Angew. Chem. Int. Ed. 2018, 57, 1903-1907; e) Z. L. Pianowski, Chem.- Eur. J. 2019, 25, 5128-5144.
[11] Z. Qiu, H. Yu, J. Li, Y. Wang, Y. Zhang, Chem. Commun. 2009, 33423344

[12] a) Y.-L. Zhao, J. F. Stoddart, Langmuir 2009, 25, 8442-8446; b) S Tamesue, Y. Takashima, H. Yamaguchi, S. Shinkai, A. Harada, Angew. Chem. Int. Ed. 2010, 49, 7461-7464; c) G. Davidson-Rozenfeld, L. Stricker, J. Simke, M. Fadeev, M. Vázquez-González, B. J. Ravoo, I. Willner, Polym. Chem. 2019, 10, 4106-4115; d) A. Tabet, R. A. Forster, C. C. Parkins, G. Wu, O. A. Scherman, Polym. Chem. 2019, 10, 467 472.

[13] J. T. van Herpt, M. C. Stuart, W. R. Browne, B. L. Feringa, Chem. -Eur J. 2014, 20, 3077-3083.

[14] a) J. E. Stumpel, B. Ziółkowski, L. Florea, D. Diamond, D. J. Broer, A. P. Schenning, ACS Appl. Mater. Inter. 2014, 6, 7268-7274; b) C. Li, A Iscen, L. C. Palmer, G. C. Schatz, S. I. Stupp, J. Am. Chem. Soc. 2020, $142,8447-8453$

[15] a) K. Peng, I. Tomatsu, A. Kros, Chem. Commun. 2010, 46, 4094-4096; b) A. A. Beharry, G. A. Woolley, Chem. Soc. Rev. 2011, 40, 4422-4437; c) Y. Huang, Z. Qiu, Y. Xu, J. Shi, H. Lin, Y. Zhang, Org. Bio. Chem. 2011, 9, 2149-2155; d) T. M. Doran, D. M.; Ryan, B. L. Nilsson, Polym. Chem. 2014, 5, 241-248; e) A. M. Rosales, K. M. Mabry, E. M. Nehls, K. S. Anseth, Biomacromol. 2015, 16, 798-806; f) Z. L. Pianowski, J. Karcher, K. Schneider, Chem. Commun. 2016, 52, 3143-3146; g) F. Xie, L. Qin, M. A. Liu, Chem. Commun. 2016, 52, 930-933; h) I.-N. Lee, O. Dobre, D. Richards, C. Ballestrem, J. M. Curran, J. A. Hunt, S. M. Richardson, J. Swift, L. S. Wong, ACS. Appl. Mater. Inter. 2018, 10, 7765-7776; i) A. M. Rosales, C. B. Rodell, M. H. Chen, M. G. Morrow, K. S. Anseth, J. A. Burdick, Bioconjugate Chem. 2018, 29, 905-913; j) M. E. Roth - Konforti, M. Comune, M. Halperin - Sternfeld, I. Grigoriants, D. Shabat, L. Adler - Abramovich, Macromol. Rapid. Commun. 2018, 39, 1800588; k) C. Wang, K. Hashimoto, R. Tamate, H. Kokubo, M. Watanabe, Angew. Chem. Int. Ed. 2018, 57, 227-230; I) L. Li, J. M. Scheiger, P. A. Levkin, Adv. Mater. 2019, 31, 1807333; m) M. S. de Luna, V. Marturano, M. Manganelli, C. Santillo, V. Ambrogi, G. Filippone, P. Cerruti, J. Colloid. Interf. Sci. 2020, 568, 16-24; n) N. Higashi, R. Yoshikawa, T. Koga, RSC Adv. 2020, 10, 15947-15954.

[16] F. Tong, S. Chen, Z. Li, M. Liu, R. O. Al-Kaysi, U. Mohideen, Y. Yin, C. J. Bardeen, Angew. Chem. Int. Ed. 2019, 58, 15429-15434.

[17] a) J. V. Accardo, J. A. Kalow, Chem. Sci. 2018, 9, 5987-5993; b) J. Karcher, Z. L. Pianowski, Chem.- Eur. J. 2018, 24, 11605-11610; c) F. Zhao, A. Bonasera, U. Nöchel, M. Behl, D. Bléger, Macromol. Rapid. Commun. 2018, 39, 1700527; d) X. Tong, Y. Qiu, X. Zhao, B. Xiong, R. Liao, H. Peng, Y. Liao, X. Xie, Soft Matter 2019, 15, 6411-6417.

[18] C. W. Chu, L. Stricker, T. M. Kirse, M. Hayduk, B. J. Ravoo, Chem. Eur. J. 2019, 25, 6131-6140.

[19] a) C. E. Weston, R. D. Richardson, P. R. Haycock, A. J. P. White, M. J. Fuchter, J. Am. Chem. Soc. 2014, 136, 11878-11881; b) J. Calbo, C. E. Weston, A. J. P. White, H. S. Rzepa, J. Contreras-García, M. J. Fuchter, J. Am. Chem. Soc. 2017, 139, 1261-1274; c) S. Crespi, N. A. Simeth, B. König, Nat. Rev. Chem. 2019, 3, 133-146; d) R. S. Gibson, J. Calbo, M. J. Fuchter, Chem. Photo. Chem. 2019, 3, 372-377; e) M. A. Gerkman, R. S. Gibson, J. Calbo, Y. Shi, M. J. Fuchter, G. G. Han, J. Am. Chem. Soc. 2020, 142, 8688-8695.

[20] C.-W. Chu, B. J. Ravoo, Chem. Commun. 2017, 53, 12450-12453.

[21] a) D. K. Kumar, D. A. Jose, P. Dastidar, A. Das, Langmuir, 2004, 20 , 10413-10418. b) J. Shi, Y. Gao, Z. Yang, B. Xu, Beilstein J. Org. Chem. 2011, 7, 167-172; b) A. J. Kleinsmann, B. J. Nachtsheim, Chem. Commun. 2013, 49, 7818-7820.

[22] M. A. Spackman, D. Jayatilaka, CrystEngComm 2009, 11, 19-32

[23] A. D. Martin, J. Britton, T. L. Easun, A. J. Blake, W. Lewis, M. Schröder, Cryst. Grow. Des. 2015, 15, 1697-1706.

[24] D. J. Adams, M. F. Butler, W. J. Frith, M. Kirkland, L. Mullen, P. Sanderson, Soft Matter 2009, 5, 1856-1862.

[25] S. R. Raghavan, B. H. Cipriano in Molecular gels (Eds.: R. G. Weiss, P. Terech), Springer, Dordrecht, 2006; pp. 241-252.

[25] A. D. Martin, J. P. Wojciechowski, A. B. Robinson, C. Heu, C. J. Garvey, J. Ratcliffe, L. J. Waddington, J. Gardiner, P. Thordarson, Sci. Rep. 2017, 7, 43947.

[26] K. Park, J. Controlled Release 2014, 190, 3-8. 


\section{Entry for the Table of Contents}

Insert graphic for Table of Contents here.

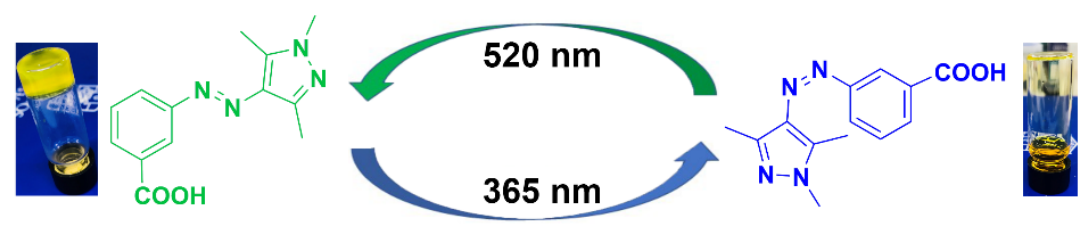

Tiny switchable gelators: Small photoswitchable (MW $258 \mathrm{~g} / \mathrm{mol}$ ) arylazopyrazoles form self-assembled gels in water that can be reversibly cycled between a gel and solution state using two different excitation wavelengths that causing "thinning" of the gel fibers upon the light induced $E$ to $Z$ isomerisation.

Institute and/or researcherTwitter usernames: @FayazAliLarik1 @LucyFillbrook @SandraNurttila @doc_martinaus @JonBeves @PalliThordarson 